\title{
Um lugar na escola para a expressividade musical: etnografia sensorial em colaboração com adolescentes
}

\author{
Ana Paula Batista Pina* \\ Fernanda Müller ** \\ Marta Morgade Salgado***
}

\section{Resumo}

O presente trabalho descreve a análise de experiências musicais de adolescentes de 12 a 15 anos de idade, estudantes de uma turma de sétimo ano do Ensino Fundamental de um centro público de Educação Integral. A pesquisa de campo foi estruturada por meio de três oficinas, que promoveram a produção coletiva de fotografias, sons e vídeos relacionados às experiências musicais desses adolescentes. Foi composto um mosaico metodológico, que se baseou preponderantemente na etnografia sensorial. Entrevistas que incorporaram photovoice foram consideradas como componentes catalisadores de narrativas. Três categorias de análise foram construídas: a relação de adolescentes com a música, cultura de pares em interface com a cultura escolar e aprendizagem colaborativa. Por meio da promoção dessas experiências sensoriais foi possível compreender como os adolescentes se expressam e como se relacionam com seus pares.

Palavras-chave: Adolescentes. Cultura Escolar. Etnografia Sensorial. Música.

* Graduada em Pedagogia pela Universidade de Brasília (UnB).

** Doutora em Educação pela Universidade Federal do Rio Grande do Sul (UFRGS). Professora da Universidade de Brasília (UnB).

${ }^{* * *}$ Doutora em Psicologia pela Universidad Autónoma de Madrid (UAM). Professora da Universidad Autónoma de Madrid (UAM). 


\section{Introdução}

O presente artigo apresenta a análise de experiências de adolescentes de 12 a 15 anos de idade relacionadas à sua expressividade e à música. Os participantes envolvidos na pesquisa ${ }^{4}$ são estudantes de uma turma de sétimo ano do Ensino Fundamental (Anos Finais) de um centro público de Educação Integral de Brasília/Distrito Federal. O objetivo geral do estudo foi analisar o modo pelo qual adolescentes se expressam e percebem a música, tanto na escola como em outros contextos da vida social.

Compreendemos a adolescência como uma transição que não mais representa a infância, tampouco a juventude. Neste artigo o termo adolescência é utilizado para caracterizar uma categoria etária e social à qual os sujeitos desta pesquisa pertencem, pois não mais se sentem parte do universo infantil, mas ainda não se consideram ou são considerados jovens. O Estatuto da Criança e do Adolescente (ECA), Lei $\mathrm{n}^{\mathrm{o}}$ 8.069, de 13 de julho de 1990, em seu art. $2^{\circ}$, define adolescente como o sujeito de idade entre 12 e 18 anos. Já o Estatuto da Juventude, Lei no 12.852, de 5 de agosto de 2013, afirma, em seu art. $1^{\circ}$, que jovem é toda a pessoa de 15 a 29 anos de idade. Considerando ambas as leis, pessoas de idade entre 15 e 18 anos têm direitos previstos tanto pelo ECA quanto pelo Estatuto da Juventude. Essa sobreposição de definições e garantias legais mostra que a categoria adolescência compreende uma transição.

William A. Corsaro (2011) conceitua a infância como uma construção social, que deve ser compreendida a partir de outras categorias, tais como classe social, gênero e grupo de idade. Essas categorias vinculam-se aos universos das crianças, consideradas "agentes ativos que constroem suas próprias culturas e contribuem para a produção do mundo adulto" (CORSARO, 2011, p. 16). Ao tratar de juventude, Mario Margulis (2001, p. 45, tradução nossa) afirma que se trata de "uma condição definida pela cultura, mas que tem uma base material vinculada à idade", sendo também historicamente construída. Tanto infância como juventude estão presentes em "todas as classes sociais", as quais "têm jovens que se diversificam em vários agrupamentos como portadores de códigos culturais distintos expressos em sua aparência e comportamento" (MARGULIS, 2001, p. 45, tradução nossa). Em termos sociológicos, poderíamos afirmar que a adolescência se caracteriza como uma transição, um entrelugar, que para Homi Bhabha (2003, p. 20, grifo do autor) se localiza "nos excedentes da soma das 'partes' da diferença”.

Aplicamos a essa categoria transitória algumas conclusões dos estudos de juventude. Carlos Henrique Martins e Paulo Cesar Carrano (2011, p. 51) afirmam que existe uma tendência do senso 
comum em nomear o jovem como um sujeito em construção - o que também identificamos em relação à criança e ao adolescente -, como um "sujeito que será sem nunca ter sido". Para esses autores,

pensamos o jovem como a possibilidade de um futuro melhor, mas não constituímos as oportunidades de a juventude se reconhecer como tal potencialidade concreta de mudança no tempo presente. (MARTINS; CARRANO, 2011, p. 51).

Logo, é necessário conceber tanto jovens como adolescentes como sujeitos ativos, produtores de sua própria identidade e cultura. Igualmente, Juarez Dayrell (2007, p. 1.107) afirma que o jovem deve ser compreendido em sua "diversidade, [que] apresenta características, práticas sociais e um universo simbólico próprio que o diferenciam em muito das gerações anteriores”. Aplicamos aos adolescentes essa mesma premissa.

As culturas juvenis, que podem ser vinculadas às culturas de pares adolescentes, são construídas coletivamente pelos sujeitos desta categoria e estão em constante processo de mudança. Carrano (2005) defende o uso do termo "culturas juvenis" quando se refere à diversidade de identidades dentro da categoria etária e social, que precisa ser considerada inclusive dentro da escola. Para o autor, "seria errôneo pressupor a existência de uma única cultura juvenil na escola” (CARRANO, 2005, p. 154).

A partir desse entendimento, buscamos compreender como ocorrem as dinâmicas, relações e atividades expressivas e musicais dos adolescentes. Considerando as variáveis sociais, econômicas e geográficas no desdobramento e organização das atividades musicais, percebemos o sentido que elas tomam no desenvolvimento e construção de identidades, tanto individuais como coletivas.

Assim, organizamos este artigo em três seções. A primeira diz respeito à descrição da metodologia, quando buscamos localizar o trabalho a partir de um olhar da etnografia sensorial (PINK, 2009, 2010, 2011). Como forma de registro, além de considerarmos as produções coletivas dos adolescentes durantes as três oficinas, optamos pela realização de notas de campo e de entrevistas (LUKER, 2008). Para a realização das entrevistas, utilizamos o método de photovoice, proposto por Melvin Delgado (2015), a fim de catalisar experiências vividas e narradas pelos adolescentes. Na segunda seção apresentamos a análise de três categorias, de forma a estabelecer uma relação entre o que observamos durante as oficinas e as narrativas dos adolescentes durante as entrevistas. Por fim, na terceira seção, apresentamos algumas conclusões, evidenciando as questões principais encontradas no decorrer deste trabalho e as que ainda podem ser observadas em estudos posteriores. Buscamos tratar os sujeitos pesquisados como ativos no processo de construção de identidades individuais e de pares. 


\section{Etnografia sensorial e colaboração experimental com adolescentes}

Organizamos a pesquisa de campo no segundo semestre de 2014 e a estruturamos por meio de três oficinas, cujos encontros previram uma reunião de apresentação do projeto e dos pesquisadores e sete encontros posteriores de 1h20min. Já é lugar comum a atenção às questões éticas envolvidas na pesquisa, por isso consideramos desde o primeiro momento em campo a necessidade de construção de vínculo e confiança com os sujeitos envolvidos. Todas as etapas da pesquisa de campo foram negociadas, respeitando o tempo disponibilizado pela escola, para que os sujeitos compreendessem como ocorreriam as atividades e de que forma participariam. Pautamo-nos em alguns argumentos de Carvalho e Müller (2010, p. 73), como por exemplo, o "exercício da escuta", pois valorizamos a singularidade dos envolvidos e os concebemos como "sujeitos coparticipantes e coprodutores da e na pesquisa". Desta forma, propiciamos uma maior interação de pesquisadores e adolescentes, visto que a escuta foi também compreendida como um ato político.

Procuramos investigar de que forma os sujeitos se organizavam, como se relacionavam entre si e com a música, as experiências geradas a partir da proposta das oficinas e sua expressividade. As oficinas foram estruturadas como laboratórios de experimentação sonora e envolveram atividades ligadas à produção de fotografias, sons e vídeos relacionados à música. Cada uma das três oficinas foi ministrada por especialistas das áreas de fotografia, som e vídeo, tendo como objetivo apoiar, por meio da apresentação de experiências e softwares, a subsequente produção de materiais pelos próprios adolescentes. Para possibilitar esse trabalho, a equipe de pesquisa disponibilizou um computador portátil a cada um dos cinco grupos. As atividades foram então realizadas em pequenos grupos e sempre concluídas com a elaboração de um produto, que era postado em rede social de acesso restrito, a fim de promover a divulgação dos trabalhos entre os participantes e a equipe de pesquisa.

A primeira oficina compreendeu dois encontros e promoveu a construção de narrativas fotográficas. Primeiramente, o especialista expôs suas fotografias, dando base a um trabalho posterior com imagens. Posteriormente, os grupos puderam construir seus próprios relatos fotográficos, escolhendo fotografias que faziam parte de suas vidas e as postando em rede social para que pudessem ser compartilhadas entre todos os grupos.

A segunda oficina também compreendeu dois encontros. Para o primeiro encontro, um músico foi convidado a narrar a sua história com a música. No encontro subsequente foi proposto aos grupos que elaborassem sons a partir de suas percepções e experiências, utilizando ferramentas de edição do 
software Audacity. Assim, foram produzidas variadas paisagens sonoras, que expressavam os diversos sons pelos quais os grupos mais se identificavam, também publicadas em rede social de acesso restrito.

Já a terceira oficina foi composta por três encontros e teve como objetivo a edição de um vídeo. Essa oficina contou com o know-how de um especialista, que compartilhou a experiência de edição de vídeos por meio do software Movie Maker. Para o primeiro encontro, o especialista compartilhou exemplos de vídeos por ele produzidos, ou mesmo encontrados em sítios da Internet. Esse momento funcionou como catalisador para os grupos, que passaram a produzir os seus vídeos nos dois encontros subsequentes, contando com os materiais já produzidos, ou seja, as fotografias e os sons. E com isso, no oitavo encontro, os grupos finalizaram a edição dos vídeos e puderam também os postar em rede social, a fim de que todos os participantes conseguissem assistir às produções coletivas e comentá-las.

Durante a produção de materiais visuais, sonoros e midiáticos nas oficinas, os adolescentes puderam refletir sobre a sua relação com a música, tanto na escola como na vida social mais ampla, de forma coletiva, junto com os seus pares. Com isso, consideramos o que Nadine Schäfer (2012, p. 149, tradução nossa) propõe, ou seja, que os "métodos visuais não sejam utilizados simplesmente para gerar dados visuais, mas também como uma ferramenta para reflexão, envolvimento e representação de e pelos participantes no processo de pesquisa".

Construímos a investigação com base na concepção de Pink (2009, 2010, 2011) acerca da etnografia sensorial, uma prática que envolve "compromissos multissensoriais incorporados com outros [...] e com os seus ambientes sociais, materiais, discursivos e sensoriais" (PINK, 2009, p. 25-26, tradução nossa). A autora ainda explica que a etnografia sensorial pode incorporar outras mídias e representações, tais como vídeos e outros materiais audiovisuais.

Os materiais produzidos possibilitaram o desenvolvimento de um trabalho etnográfico sensorial, já que previram contato com a expressividade e os diversos significados dados pelos sujeitos. Mesmo não sendo "associados a instrumentos da etnografia acadêmica clássica" (PINK, 2011, p. 439, tradução nossa), foram relevantes para a compreensão do universo pesquisado. O compartilhamento dos materiais produzidos em rede social funcionou como uma ferramenta de comunicação, pois ampliou ainda mais as possibilidades de interação fora do ambiente escolar. Com isso promovemos uma nova forma de comunicação entre os adolescentes, por meio do contato e do compartilhamento de experiências sensoriais construídas e percebidas coletivamente. Assim, à medida que os adolescentes vivenciavam esses momentos, conseguíamos perceber diferentes formas de expressividade e relações entre pares. 
Pink (2010, p. 331, tradução nossa) define a etnografia sensorial como essencialmente interdisciplinar no campo da pesquisa social, e, por isso, abrange saberes de diversas áreas do conhecimento para a interpretação de dados. Dessa forma, as reflexões geradas a partir das experiências sensoriais de adolescentes precisam ser percebidas também por meio dos sentidos pelo pesquisador. Por isso, não nos restringimos a obter apenas dados factuais, mas buscamos compreender todo o processo que envolveu a construção dos materiais e a interações de pares.

Garantimos aproximações de pares e contato com os diversos sentidos, tanto visuais quanto sonoros e midiáticos, para que pudessem explorar essas relações em sua inteireza, sem se preocuparem em estar sendo avaliados. Para documentar o processo, optamos pela descrição detalhada de notas de campo, que se basearam em observações sistemáticas sobre as ações dos sujeitos durante as oficinas. Luker (2008, p.164, tradução nossa) destaca a importância das notas de campo, definindo-as como "ferramentas preciosas e temidas pelos pesquisadores de campo", pois, como mostra a autora, cabe aos investigadores registrar tudo o que acontece nos momentos compartilhados com os sujeitos de pesquisa, para que depois procedam à análise.

Sendo assim, a cada encontro, buscávamos registrar as dinâmicas dos grupos com um olhar atento. Para isso, construímos narrativas descritivas dos processos que foram vivenciados nas oficinas, a fim de registrar interações de pares durante as negociações exigidas pela proposta, sua relação com a música e as motivações para a aprendizagem. Consideramos sempre nesses registros o que Robert Bogdan e Sari Biklen (1994) defendem, ou seja, que é preciso relatar os sujeitos, a reconstrução dos diálogos, o espaço físico, as atividades, os relatos particulares e o próprio comportamento do observador.

Posteriormente, foram conduzidas entrevistas com os participantes disponíveis, de forma a complementar as informações das notas de campo. Compreendemos as entrevistas como narrativas, já que tratam sobre "o que a pessoa que está sendo entrevistada pensa sobre o acontecido, ou pensa sobre o que poderia ter acontecido, ou até mesmo sobre o que queria que tivesse acontecido" (LUKER, 2008, p. 167, tradução nossa). Logo, uma entrevista individual foi realizada com 18 adolescentes. De modo a subsidiar a reflexão, lançamos mão dos materiais produzidos por cada um dos cinco grupos, isto é, fotografias, sons e vídeos, como catalisadores de uma conversa informal. Inspiramo-nos no procedimento de photovoice, que, de acordo com Delgado (2015, p. 20, tradução nossa), pode ser definido basicamente como "o uso de equipamentos fotográficos, geralmente digitais, para capturar uma imagem visual e então transformá-la em um veículo para gerar informações e discussões". Delgado (2015, p. 24, tradução nossa) ainda afirma que o método de photovoice pode ser chamado de 
“escuta comunitária, por causa de sua capacidade de penetrar nas comunidades” e, com isso, compreender os processos que ocorrem em diferentes grupos sociais. Portanto, consideramos a voz dos participantes para a compreensão do que acontecia durante as oficinas.

No momento das entrevistas, acessávamos a rede social e mostrávamos aos adolescentes as fotografias, assim como os sons e vídeos, que seus grupos haviam produzido e editado. Em seguida, pedíamos que narrassem o que aquelas produções representavam para eles e como elas se conectavam com suas vidas, de forma individual e coletiva. Os adolescentes então narravam o que tinham percebido e o que os seus colegas haviam discutido sobre aquelas imagens, sons e/ou vídeos. Marisol Clark-Ibanez (2004, p. 1.512, tradução nossa) afirma que "as fotografias podem facilitar o relacionamento entre o pesquisador e o entrevistado". Logo, com as fotografias em mãos, ambos têm instrumentos mais concretos para iniciar uma conversa e, por sua vez, indagações. Isto permitiu uma melhor fluidez na fala dos adolescentes e possibilitou que eles relembrassem fatos particulares de cada momento das atividades das oficinas. Assim, cada um pôde expressar suas percepções acerca do trabalho desenvolvido e de sua relação com a pesquisa e com os pares. Consideramos as fotografias como narrativas próprias, decorrentes de um processo investigativo que os próprios adolescentes já tinham realizado sobre a sua experiência com a música. Como foram compartilhadas na rede social, já tinham sido discutidas, pensadas e expostas aos pares publicamente (de quem também já tinham recebido algum retorno). Os materiais produzidos, portanto, não são simples catalisadores externos para a sua participação na investigação.

Com base na produção das narrativas fotográficas, dos sons e dos vídeos produzidos pelos adolescentes, oito registros densos de notas de campo e dezoito entrevistas foram realizados. A partir da análise destes dados, identificamos categorias para compreender a expressividade dos sujeitos. Pretendemos apresentar um novo olhar para a pesquisa social, sobretudo quando o campo de investigação é o escolar, valorizando a percepção dos adolescentes como sujeitos ativos, que compreendem, constroem e refletem sobre suas ações, podendo assim ser também entendidos como coprodutores de dados.

\section{Cultura de pares e colaboração na aprendizagem}

Por meio do material sensorial construído a partir dos recursos fotográficos, sonoros e midiáticos na escola, embora utilizando recursos que extravasam as possibilidades que esse espaço 
oferece aos adolescentes, percebemos como eles compreendem a música, como se relacionam entre si, como se expressam e o que os motiva a aprender. Portanto, os procedimentos metodológicos garantiram a multiplicidade de dados gerados nas oficinas, tanto nas notas de campo quanto nas narrativas apresentadas durante as entrevistas.

Os adolescentes mostraram desde o começo que estavam dispostos a se envolver nas oficinas, sobretudo por estas se diferenciarem da proposta de arte do currículo do sétimo ano, cuja ênfase era dada ao teatro e à dança. Em um episódio, alguns construíram sons ao bater levemente nas carteiras, de forma rítmica, o que foi acompanhado por parte do grupo. Em outros momentos, observamos que dançavam durante as oficinas, ou escutavam músicas enquanto construíam seus materiais. Percebemos que a música possibilitava a criação e provocava novas ideias nas etapas de construção das narrativas fotográficas, sonoras e/ou midiáticas. Pink (2009, p. 134, tradução nossa) destaca que "representações etnográficas e artísticas podem criar uma sensação de intimidade suficientemente poderosa para convidar a compreensão empática e comunicar o conhecimento experiencial”. A possibilidade de conexão entre os meios tecnológicos e as relações estabelecidas nas redes sociais foram também fatores que motivaram a grande participação dos adolescentes durante as oficinas.

Estabelecemos alguns pontos comuns que foram basilares para a construção de três categorias de análise, quais sejam: a) relação com a música; b) cultura de pares; e c) aprendizagem colaborativa. Apresentamos, a seguir, a análise de cada uma dessas categorias, a partir da convergência entre as entrevistas e os registros de campo.

\section{Relação com a música}

Compreender de que forma os adolescentes se relacionam com a música foi um dos nossos objetivos. Para isso, é necessário considerar que o termo "adolescente" foi percebido como um construto sócio-histórico, que diz respeito a uma categoria etária e social transitória, um entre-lugar, e que possui uma produção cultural relativamente própria, que se expressa tanto na escola como em outros contextos sociais. Corroborando esse entendimento, percebemos nas oficinas que os adolescentes, em sua grande maioria, apresentaram referências musicais procedentes da família, algumas do convívio com os colegas de classe; e ainda outras, oriundas de suas próprias escolhas pessoais.

Quanto às referências familiares, Cléopâtre Montandon (2005) descreve a influência que pais e mães exercem sobre os filhos, e como esse vínculo familiar pode ser percebido nas ações cotidianas de 
crianças, em nosso caso, de adolescentes. Essa influência da família vai além dos gostos musicais, pois está presente todo o tempo na vida desses sujeitos, manifestando-se na forma de cuidado, de controle ou mesmo de motivação para com os filhos. Essas relações vinham à tona nos momentos em que os adolescentes construíam narrativas e utilizavam a música como recurso facilitador do processo, ocasiões em que podiam expressar suas identidades e culturas, formadas a partir de influências diversas.

Dos dezoito entrevistados, dezesseis afirmaram gostar de ouvir música, dentre os quais quatorze afirmaram gostar de estilos musicais variados. Como afirmou Amanda": "gosto de tudo, menos de rock"; Carolina alegou que gosta de ouvir "rap, sertanejo, evangélicas e alguns tipos de rock, até de axé”. Já Fernando e Paulo falaram que gostam apenas de ouvir rock. Apenas dois meninos afirmaram que não gostavam de qualquer estilo musical. Durante as entrevistas, também descobrimos que duas meninas gostavam de música porque seus pais são músicos; ambas afirmaram que os tomam como referências em suas escolhas musicais.

De maneira geral, percebemos que os adolescentes tomaram a música como fonte de inspiração para a execução das atividades das oficinas. Em seu depoimento, Alice relatou a importância das oficinas de música: "os adolescentes têm muito a ver com música, porque é um jeito de renovar, de se mostrar, de ser mais a pessoa", identificando com isso a questão da formação da identidade de adolescente relacionada ao gosto musical. Ainda para ela, "o adolescente e a música estão relacionados, os dois são pactos, então um melhora o outro". Já Raquel afirmou que gostava das atividades das oficinas por ser um momento em que ela e suas amigas podiam se reunir e cantar, tornando-se um momento prazeroso para seu grupo de colegas. Fernando disse que a música foi muito importante para as oficinas, pois permitiu que ele e seus colegas vivenciassem o que estava acontecendo, relacionando sempre as músicas das quais gostavam.

Todos esses depoimentos nos permitiram perceber como a música é tratada pelos adolescentes. Notamos que ela está inserida em suas vidas como algo rotineiro e que pode ser fonte de inspiração para eles. Afinal, como afirma Dayrell (2007):

A dimensão simbólica e expressiva tem sido cada vez mais utilizada como forma de comunicação e de um posicionamento diante de si mesmos e da sociedade. A música, a dança, o vídeo, o corpo e seu visual, dentre outras formas de expressão, têm sido os mediadores que articulam jovens que se agregam para trocar ideias, para ouvir um "som", dançar, dentre outras diferentes formas de lazer. (DAYRELL, 2007, p. 1.109).

As experiências sensoriais possibilitaram o envolvimento dos sujeitos durante as oficinas. Pink (2009, p. 134, tradução nossa) destaca que a "O uso de práticas e processos narrativos e tecnológicos PERSPECTIVA, Florianópolis, v. 35, n. 3, p. 702-721, jul./set.. 2017 
diversos criam rotas e reúnem sensações, emoções, significados, reflexividade, descrições, argumentos e teorias selecionados", o que nos permitiu compreender identidades coletivas construídas em culturas de pares e de que forma adolescentes valorizam e percebem a música em suas vidas.

Muitas das ações dos adolescentes durante as oficinas tinham como base a música. Essa influência se manifestava das formas mais variadas possíveis, como por exemplo, quando alguns deles dançavam para tentar chamar a atenção de uma menina da turma, ou mesmo cantavam junto com seus colegas as músicas de suas preferências. Até influências mais intrínsecas, como o uso criativo das roupas do uniforme escolar e assessórios, formas próprias de caminhar, ou ainda a expressão de uma transgressão ao que lhes era exigido pela escola.

Os adolescentes transformam as suas relações e se expressam das mais variadas formas, ainda que em um ambiente formal como é o da escola. Dayrell (2007) sugere a necessidade de compreender esses sujeitos, assim como de mudar a escola. Desta forma, ele propõe "uma mudança do eixo da reflexão, passando das instituições educativas para os sujeitos jovens, onde é a escola que tem de ser repensada para responder aos desafios que a juventude nos coloca” (DAYRELL, 2007, p. 1.107).

\section{Cultura de pares}

As formas de interação de adolescentes estão conectadas ao contexto e às relações sociais estabelecidas por eles. Corsaro (2009) destaca esse tipo de relação com o termo "cultura de pares", que apesar de se referir à interação de crianças pode ser também percebida nas relações entre adolescentes. Corsaro define (2009, p. 32) cultura de pares como "um conjunto estável de atividades ou rotinas, artefatos, valores e interesses que as crianças [no nosso caso, adolescentes] produzem e compartilham na interação com seus pares”. Essa relação pode ser observada na escola, onde os adolescentes passam a maior parte de sua rotina com os colegas, compartilhando tarefas e estabelecendo interesses em comum.

Para Corsaro (2009), a interação potencializa processos de desenvolvimento individual e social. Os adolescentes, sendo continuamente formados como sujeitos plurais, constituem-se conforme suas singularidades e também em razão de fatores externos a eles. Maria Carmem S. Barbosa (2007, p. 1.065) destaca que é nesse processo que o indivíduo se socializa, definindo, para isso, o termo socialização como "um processo contínuo de inserção cultural, [...] compreendida como a construção de significados, partilhados por outros ou não, sustentados em práticas da vida individual e social”. 
Dayrell (2007) afirma que a sociabilidade é outra condição do ser jovem, o que também observamos entre os adolescentes. Para o autor,

A sociabilidade expressa uma dinâmica de relações, com as diferentes gradações que definem aqueles que são os mais próximos ("os amigos do peito") e aqueles mais distantes (a "colegagem"), bem como o movimento constante de aproximações e afastamentos, numa mobilidade entre diferentes turmas ou galeras. (DAYRELL, 2007, p. 1.110).

Com isso, o adolescente vai se constituindo como sujeito ativo, que não apenas assimila o que lhe é ensinado mas também transforma essa informação ou norma social e age sobre ela. Esta afirmativa vai ao encontro do processo de "reprodução interpretativa" (CORSARO; EDER, 1990; CORSARO, 2009), que é definido como um "processo criativo de apropriação" das regras sociais (CORSARO; EDER, 1990, p. 200, tradução nossa).

Todavia, as interações estabelecidas na "cultura de pares", que observamos entre os adolescentes, têm mais uma particularidade, qual seja, o local onde ocorrem - na escola. As interações também estão sempre relacionadas à cultura escolar, o que Julia Dominique (2001) descreve como:

Um conjunto de normas que definem conhecimentos a ensinar e condutas a inculcar, e um conjunto de práticas que permitem a transmissão desses conhecimentos e a incorporação desses comportamentos; normas e práticas coordenadas a finalidades que podem variar segundo as épocas (finalidades religiosas, sociopolíticas ou simplesmente de socialização). (DOMINIQUE, 2001, p. 10, grifos do autor).

Durante as oficinas, foi comum perceber interações de adolescentes, tanto na instituição escolar como nas relações de “colegagem” (DAYRELL, 2007, p. 1.111) estabelecidas com os pares. Eles construíam regras informais, acionavam práticas cotidianas e referências externas para dentro da escola, o que repercutia tanto em um processo de influência mútua como de transformação de normas externas ao grupo.

Os adolescentes se agrupavam conforme afinidades e interesses. Por exemplo, havia um grupo de meninos que se agrupava porque gostava de jogos de videogame; outro grupo de meninas se reunia porque gostava de música e maquiagem; já um terceiro grupo era conhecido, talvez estigmatizado, por suas transgressões. E assim conseguíamos perceber identidades formadas nas culturas de pares, que podiam ser percebidas no pátio da escola e no momento do intervalo do almoço.

Em todo o tempo, era notável o estabelecimento de cultura de pares. Nas oficinas, percebemos interações diversas dos membros dos grupos e destes com toda a turma. O modo como se organizavam nos grupos, a postura do suposto líder e a forma como expunham referências familiares aos colegas foram percebidos em todos os encontros. No que diz respeito ao modo de agir aprendido em âmbito 
familiar, Montandon (2005, p. 494) destaca que os sujeitos recebem as influências de seus próprios familiares, "selecionam, interpretam as experiências e constroem estratégias que podem conduzir a mudanças nas suas relações", mesmo nas relações externas ao ambiente familiar, neste caso, na escola.

Buscamos também observar de que forma os adolescentes interagiam e principalmente lidavam com os conflitos e negociações para a construção dos materiais para as oficinas. Conflitos ocorreram desde o primeiro encontro, quando foi solicitado que se organizassem em grupos e dessem um nome a eles. Nesse momento, Amanda disse que essa formação de grupos "não daria certo". Ficou clara a postura cética de Amanda, que tinha como referência outros trabalhos escolares de grupo, dos quais ela já tinha participado. Isto evidenciou uma postura da turma percebida por ela e que deixou claro uma cultura escolar de pares, referente ao não envolvimento nos trabalhos em equipe. Mas, em seguida, depois de um combinado entre eles, os grupos se organizaram para a execução das atividades das oficinas.

Houve também uma disparidade quanto ao número de integrantes em cada um dos grupos, pois alguns queriam formá-lo com apenas dois membros e outros com cinco, porém, ao final do primeiro encontro, eles conseguiram se organizar com quatro ou cinco integrantes, como havia sido sugerido. Para que essa combinação fosse seguida, eles precisaram compreender que os grupos não podiam ser extensos ou muito reduzidos, como parecia ser de costume. Tínhamos como limitação a quantidade de notebooks, cinco, e parecia-nos que um equilíbrio entre a quantidade de membros por cada grupo garantiria o uso do equipamento por todos. Para isso, os adolescentes precisaram reagrupar-se, a fim de que pudessem se adequar a uma nova forma de organização, da qual eles não estavam acostumados e que lhes foi proposta. De alguma forma, a proposta rompeu com a cultura escolar, dando mais foco a um trabalho de investigação nos grupos de pares.

Dominique (2001) sustenta que é comum às culturas escolares o surgimento de relações conflituosas inerentes aos indivíduos, afinal é na escola que esses sujeitos têm momentos de encontro com seus pares, que vão além da família, com os quais podem estabelecer novas relações. Essas relações são influenciadas pela organização e estrutura escolares e pelos sujeitos que as constituem. Assim, a cultura de pares é também formada na cultura escolar, que sempre é compartilhada.

Em certos encontros, percebemos outros conflitos na interação, principalmente na divisão de atividades dentro dos grupos. Ficou claro que existia sempre alguém que liderava a execução das tarefas e tentava impor suas ideias sobre o que seria melhor e sobre o que deveria ser descartado pelo grupo na produção do material. Isso pôde ser notado no quinto encontro, quando Diego se apossou do computador e ficou a maior parte do tempo produzindo o material sem consultar os demais colegas do 
grupo. No sétimo encontro, Laura também ficou à frente do computador do grupo, produzindo o vídeo, sem contar com a participação de suas colegas. Essa percepção corrobora o entendimento de Fabiany Silva (2006, p. 203), de que "o modo como a escola vem se organizando tem reforçado mecanismos geradores de adaptação e dominação".

Apesar desses conflitos observados durante as oficinas, os adolescentes os entendiam como uma forma de participação colaborativa. Em dez entrevistas, capturamos narrativas de que as tarefas eram realizadas de forma coletiva e que todos os integrantes do grupo participavam de sua elaboração. Por exemplo, Luana afirmou que as oficinas foram diferentes de outros trabalhos escolares realizados em grupo, pois ela achou que o grupo estava mais unido e todos participaram.

Todavia, três participantes afirmaram que os colegas tiveram dificuldades na organização grupal. Carolina assegurou que seus colegas de grupo não "queriam fazer nada" e que restava a ela fazer tudo. Podemos afirmar que Carolina assume um discurso escolar, e não da cultura de pares, pois, ao acusar os outros de não fazer nada, ou de incomodar, confronta o desvio de um comportamento esperado que os alunos assumam na escola, que é fazer algo. Já outros três afirmaram que sempre havia aqueles que dominavam o computador e não permitiam que os outros integrantes participassem de forma mais efetiva na edição dos materiais. Como foi o caso da Amanda, quando ela disse que as colegas só "faltavam brigar" para usar o computador.

Um relato interessante foi trazido por Laura, que assumiu ter ficado sempre à frente do computador e, no início, chateando-se com as colegas quando elas também queriam ter acesso a ele; depois de muito diálogo, ela passou a entender suas colegas e permitiu que elas também usassem o equipamento no momento da produção dos materiais.

Esses conflitos, negociações e relações estabelecidas entre pares na interface com a cultura escolar foram evidenciados em todos os encontros. Percebemos que os grupos desenvolviam mecanismos para solucionar divergências no processo de interação, como foi o caso do grupo de Laura. Os adolescentes buscavam sempre estabelecer regras e padrões de convívio entre eles. Ainda que se relacionassem em uma instituição formal, eles buscavam construir relações de modo mais livre, sem contar com a intervenção dos adultos nessa interação, estabelecendo com isso suas culturas de pares.

\section{Aprendizagem colaborativa}


Os adolescentes mostravam-se motivados quando um novo desafio era a eles apresentado. As atividades eram propostas a partir dos objetivos das oficinas e conduzidas conforme a percepção de cada sujeito na relação com o seu grupo. Os materiais eram produzidos com a utilização de softwares atuais e de fácil compreensão, todavia, até então, eles não tinham realizado outras atividades com tais softwares na escola. Eles expressaram interesse pelas atividades e buscavam aprender mais para produzir seus materiais. Quanto mais surgiam dificuldades para a produção desses materiais, mais eles se envolviam na execução das tarefas.

Nesse processo de apropriação de novas habilidades, era perceptível como um colega ajudava o outro. Houve casos de integrantes de grupos diferentes ajudarem outros grupos, para que todos pudessem entender como os softwares funcionavam. Por exemplo, já no oitavo encontro, havia um grupo que ainda não tinha conseguido editar o vídeo, e por isso Diego, integrante de um outro grupo, propôs-se a ajudá-lo.

Essa forma de trabalho pode ser definida a partir do conceito de aprendizagem colaborativa, ou seja, "uma estratégia de ensino que encoraja a participação do estudante no processo de aprendizagem e que faz da aprendizagem um processo ativo e efetivo" (TORRES; ALCÂNTARA; IRALA, 2004, p. 131). A incorporação desse entendimento por parte dos sujeitos da pesquisa tornou-se possível, pois o grupo compreendeu as tarefas como uma forma de expressão de suas identidades que não gerava desejo de competição, mas sim de aprendizagem e de expressão.

Com isso, podemos considerar que a aprendizagem colaborativa é efetivada quando os sujeitos se mobilizam em torno da construção de conhecimento, que é apropriado a partir da socialização desse saber. Afinal, essa estratégia de ensino deriva

de dois postulados principais: de um lado, da rejeição ao autoritarismo, à condução pedagógica com motivação hierárquica, unilateral. De outro, trata-se de concretizar uma socialização não só pela aprendizagem, mas principalmente na aprendizagem. (TORRES; ALCÂNTARA; IRALA, 2004, p. 135).

Juan Manuel González-Mohino (2015, p. 6) destaca que o processo de aprendizagem envolve todo um contexto social e deve estar vinculado à realidade dos sujeitos que aprendem. Para isso, ele destaca que essa aprendizagem pode ser efetivada no processo de compartilhamento de conhecimentos, que "implica tanto a transmissão do conhecimento técnico como o uso com que este se realiza, motivando variadas aprendizagens acerca dessa prática e as relações que se estabelecem com o mundo social" (GONZÁLEZ-MOHINO, 2015, p. 7, tradução nossa). E essa socialização de saberes e habilidades foi notória em quase todos os momentos das oficinas, quando os adolescentes 
compartilhavam suas descobertas e produções com os colegas, tendo em vista a socialização dos saberes adquiridos ao longo dos encontros e as discussões promovidas na rede social.

A motivação por aprender algo novo foi reiterada nas narrativas dos participantes. Em todas as entrevistas foram mencionadas experiências de aprendizagem com a pesquisa, bem como que a possibilidade de "aprender algo novo" os motivou a participar do projeto. Bruno achou as oficinas “divertidas", porque aprendeu a "editar vídeo e músicas". Da mesma forma, Fernando disse que as oficinas foram muito legais, "porque [a equipe de pesquisa] ensinou coisas que não tínhamos conhecimento antes". Laura, por sua vez, declarou que gostou muito das oficinas e que "é muito legal de vez em quando dar uma variada nos exercícios", referindo-se a como foram interessantes as tarefas sugeridas na pesquisa.

Logo na primeira oficina observamos que um grupo estava tão motivado que buscava de todo o jeito conseguir um sinal mais forte de Internet, para poder continuar a produção da narrativa fotográfica. Percebíamos também que, quando alguém compreendia a dinâmica da oficina, logo se empenhava em colocá-la em prática. Os conflitos, com o tempo, foram superados, já que os adolescentes passaram a compreender que poderiam distribuir as atividades e desse modo todos os integrantes dos grupos puderam participar da construção dos materiais.

Todos perceberam como foi motivador realizar essas tarefas diferenciadas, utilizando computadores, novos softwares e redes sociais. Com isso, percebemos como os sujeitos se motivaram quando as atividades propostas a eles foram desenvolvidas através de instrumentos comuns a suas realidades e interesses. Igualmente, essa aprendizagem pode ocorrer de forma colaborativa, em que todos os participantes se envolvem coletivamente em torno da efetivação de um objetivo comum.

\section{Considerações finais}

Com base na concepção de Pink $(2009,2010,2011)$ acerca de etnografia sensorial, que valoriza as diversas formas de experiências sensoriais de expressão, pudemos compreender como adolescentes se relacionam entre si e se expressam por meio da música. Essa compreensão foi gerada não apenas pelos nossos registros como pesquisadores, mas sobretudo pelo olhar e registro/produções dos adolescentes. A natureza e o processo de produção de fotografias, sons e vídeos são igualmente importantes. Esses materiais não só suscitaram ou catalisaram narrativas; estas são histórias de meninos e meninas compartilhadas durante as oficinas antes das entrevistas, que foram discutidas, debatidas e 
compartilhadas, que expressam significados sobre toda a experiência. Afinal, como afirma Pink (2009), esses diferentes métodos usados em experiências sensoriais permitem que compreendamos melhor o mundo do outro.

Percebemos, com isso, como os adolescentes se relacionam com a música e a expressam conforme suas particularidades e identidades de grupo. Os gostos musicais dos sujeitos variam por fatores intrínsecos e extrínsecos a eles. Muitos deles afirmaram que têm preferências musicais por influência familiar ou de amigos; já outros, por escolha própria. Foi evidente também que a música é um instrumento utilizado por eles durante as oficinas e que a grande maioria a usou como fonte de inspiração para a produção de seus materiais.

Outro ponto de destaque analisado neste trabalho foi a forma como os sujeitos estabeleceram interações de pares, que pode ser compreendida a partir do conceito de "cultura de pares", apresentado por Corsaro (2009) para o universo infantil e por nós indicada também como a relação constituinte de adolescentes. Em suas interações, estabelecem padrões e regras de convívio, o que determina a identidade de cada grupo. A cultura de pares era constituída em relação a uma cultura escolar, como definida por Dominique (2001) e também percebida naquela turma.

Sobre as interações, também destacamos os conflitos e negociações observados no decorrer das atividades desenvolvidas durante as oficinas. Em alguns momentos, houve divergências de opiniões e modos de fazer diferentes entre os participantes dos grupos. Todavia, as negociações precisaram ser desenvolvidas, e ao final das atividades eles entravam em um consenso, mantendo com isso o interesse do grupo.

Como modo de realizar produções coletivas, os participantes desenvolveram as atividades seguindo o modelo de aprendizagem colaborativa (TORRES; ALCÂNTARA; IRALA, 2004), que valoriza a socialização do conhecimento, evitando que este seja adquirido por meio de formas autoritárias e permitindo que possa ser conquistado na relação entre pares. Isso somente foi possível graças ao entendimento dos participantes sobre a ausência de cunho avaliativo e escolar nas atividades propostas nas oficinas (ainda que tenham sido realizadas na escola).

De forma conclusiva, podemos destacar que adolescentes colaboram para a produção de culturas e que suas identidades são socialmente construídas, tanto por fatores internos quanto externos a eles. Na constituição do ser adolescente há fortemente a influência da música como forma de expressividade e de vínculo entre pares. Com isso, voltamos nossos olhares para a compreensão desses sujeitos como seres complexos, e não apenas classificados por uma categoria etária. É válido considerar 
também que eles devem ser vistos como sujeitos ativos em suas aprendizagens e que podem comunicar seus saberes aos colegas de forma colaborativa.

* Graduada em Pedagogia pela Universidade de Brasília (UnB).

** Doutora em Educação pela Universidade Federal do Rio Grande do Sul (UFRGS). Professora da Universidade de Brasília (UnB). Coordenadora do Grupo Interdisciplinar de Pesquisa sobre a Infância - GIPI.

*** Doutora em Psicologia pela Universidad Autónoma de Madrid (UAM). Professora da Universidad Autónoma de Madrid (UAM). Membro do Grupo Interdisciplinar de Pesquisa sobre a Infância - GIPI.

Notas

${ }^{4}$ Os instrumentos metodológicos utilizados obedeceram aos procedimentos éticos estabelecidos para a pesquisa em Ciências Humanas. O projeto contou com o parecer favorável do Comitê de Ética em Pesquisa do Instituto de Ciências Humanas e Sociais da Universidade de Brasília (CEP/CHS/UnB) e recebeu financiamento do Banco Santander, no âmbito do Programa de Cooperação Interuniversitária UAM-Santander com a América Latina, e do CNPq. As autoras agradecem pelo apoio no planejamento e realização das oficinas aos seguintes pesquisadores(as) do Grupo Interdisciplinar de Pesquisa sobre a Infância (GIPI): Estevon Nagumo, Lucélia Almeida Silva e Rhaisa Naiade Pael Farias.

${ }^{5}$ Os nomes dos participantes da pesquisa são fictícios, de forma a atender as exigências do Comitê de Ética do Instituto de Ciências Humanas e Sociais da Universidade de Brasília (CEP/CHS/UnB). 


\section{REFERÊNCIAS}

BARBOSA, Maria Carmem. Culturas escolares, culturas de infância e culturas familiares: as socializações e a escolarização no entretecer destas culturas. Educação e Sociedade, Campinas, v. 28, n. 100 - Especial, p. 1059-1083, 2007.

BHABHA, Homi. O local da cultura. Belo Horizonte: UFMG, 2003.

BOGDAN, Robert; BIKLEN, Sari. Investigação qualitativa em educação: uma introdução à teoria e aos métodos. Porto, Portugal: Porto, 1994.

BRASIL. Estatuto da Criança e do Adolescente. Lei Federal no 8.069, de 13 de julho de 1990. Dispõe sobre o Estatuto da Criança e do Adolescente e dá outras providências. Diário Oficial [da] República Federativa do Brasil. Poder Executivo, Brasília, DF, 16 jul. 1990, p. 13563.

BRASIL. Estatuto da Juventude. Lei Federal n 12.852, de 05 de agosto de 2013. Institui o Estatuto da Juventude e dispõe sobre os direitos dos jovens, os princípios e diretrizes das políticas públicas de juventude e o Sistema Nacional de Juventude - SINAJUVE. Diário Oficial [da] República Federativa do Brasil. Poder Executivo, Brasília, DF, 6 ago. 2013, p. 1.

CARRANO, Paulo Cesar. Identidades juvenis e escola. In: Construção coletiva: contribuições à educação de jovens e adultos. Brasília: UNESCO, MEC, RAAAB, 2005. p. 153-163.

CORSARO, William A. A. Reprodução interpretativa e cultura de pares. In: MÜLLER, Fernanda; CARVALHO, Ana Maria Almeida (Orgs.). Teoria e prática na pesquisa com crianças: diálogos com William Corsaro. São Paulo: Cortez, 2009. p. 65-84.

CORSARO, William A. Sociologia da infância. Porto Alegre: Artmed, 2011.

CORSARO, William A.; EDER, Donna. Children’s peer cultures. Annual Review of Sociology, v. 16, p. 197-220, 1990.

CARVALHO, Alexandre; MÜLLER, Fernanda. Ética nas pesquisas com crianças: uma problematização necessária. In: MÜLLER, Fernanda. (Org.). Infância em perspectiva: políticas, pesquisas e instituições. São Paulo: Cortez, 2010. p. 65-84.

DAYRELL, Juarez. A escola "faz" as juventudes? Reflexões em torno da socialização juvenil. Educação e Sociedade, Campinas, v. 28, n. 100 - Especial, p. 1.105-1.128, 2007.

DELGADO, Melvin. Urban youth and photovoice: visual ethnography in action. New York: Oxford University, 2015.

DOMINIQUE, Julia. A cultura escolar como objeto de estudo. Revista Brasileira de História da Educação, n. 1, p. 9-43, 2001.

GONZÁLEZ-MOHINO, Juan Manuel. Aulas legítimas: Experiencia de una clase de $3^{\circ}$ de la ESO en el barrio de Aluche. 2015. 34 f. Trabalho de Conclusão de Curso (Graduação em XXXX) - 
Departamento Interfacultativo de Psicologia Evolutiva e de Educação, Universidade Autônoma de Madri, Espanha, 2015.

LUKER, Kristin. Salsa dancing into the social sciences: research in an age of info-glut. Cambridge: Harvard University, 2008.

MARGULIS, Mario. Juventud: una aproximación conceptual. In: BURAK, Solum (Org.). Adolescencia y juventud em América Latina. Cartago, África do Norte: Libro Universitario Regional, 2001. p. 41-55.

MARTINS, Carlos Henrique; CARRANO, Paulo Cesar. A escola diante das culturas juvenis: reconhecer para dialogar. Educação, Santa Maria, v. 36, n. 1, p. 43-56, 2011.

MONTANDON, Cléopâtre. As práticas educativas parentais e a experiência das crianças. Educação e Sociedade, Campinas, v. 26, n. 91, p. 485-507, 2005.

PINK, Sarah. Doing Sensory Etnography. Londres, Reino Unido: Sage, 2009.

The future of sensory anthropology/the anthropology of the senses. Social Anthropology, v. 18, n. 3, p. 331-340, 2010.

. Images, Senses and Applications: Engaging Visual Anthropology. Visual Antropology, v. 24, p. 437-454, 2011.

SCHÄFER, Nadine. Finding ways to do research on, with and for children and young people. Geography, v. 97, n. 3, p. 147-155, 2012.

SILVA, Fabiany de Cássia Tavares. Cultura escolar: quadro conceitual e possibilidades de pesquisa. Revista Educar, Curitiba, n. 28, p. 201-216, 2006.

TORRES, Patrícia; ALCÂNTARA, Paulo; IRALA, Esrom Adriano. Grupos de consenso: uma proposta de aprendizagem colaborativa para o processo de ensino-aprendizagem. Revista Diálogo Educacional, Curitiba, v. 4, n.13, p.129-145, 2004. 
A Place at School for Musical Expression: Sensory ethnography in collaboration with adolescents

\begin{abstract}
This paper describes an analysis of the musical experiences of 12-15 year-old adolescents, in a seventh grade public school class, with daylong (integral) education. The field research was organized around three workshops that promoted collective productions of photographs, and sound and video recordings related to the musical experiences of the teenagers. A methodological mosaic was built, based predominantly on sensory ethnography. Interviews that incorporated photo-voice technique were considered as a catalyzing component of the narratives developed. Three categories of analysis were identified: the relationships of adolescents with music; peer culture interfaced with the school culture; and collaborative learning. By promoting these sensory experiences it was possible to understand how the adolescents expressed themselves and related to their peers.
\end{abstract}

Key words: Adolescents. School culture. Sensorial Ethnography. Music.

Ana Paula Batista Pina

E-mail: anapaulabatistapina@gmail.com

Fernanda Müller

E-mail: fernandamuller@unb.br

Marta Morgade Salgado

E-mail: marta.morgade@uam.es
Un lugar en la escuela para la expresividad musical: etnografía sensorial en colaboración con adolescentes

\section{Resumen}

En este trabajo se describe un análisis de las experiencias musicales de un grupo de adolescentes de 12-15 años estudiantes de una clase de séptimo grado en un centro público de educación integral. La investigación de campo se estructuró a través de tres talleres que promovieron la producción colectiva de fotografías, sonidos y vídeos sobre las experiencias musicales de estos adolescentes. Se construyó un mosaico metodológico a partir de la etnografía sensorial. Las entrevistas incorporaron el photovoice considerándose como catalizador de la narrativa. Se identificaron tres categorías de análisis: la relación de los adolescentes con la música; la interconexión entre la cultura de iguales con la cultura de la escuela; y el aprendizaje colaborativo. Mediante la promoción de estas experiencias sensoriales fue posible entender cómo se expresan los adolescentes y cómo se relacionan con sus pares.

Palabras clave: Adolescentes. Cultura escolar. Etnografía Sensorial. Música.

Enviado em: 30/11/2015

Versão final recebida em:

Aprovado em: 20/11/2016 